\title{
ARTICLE
}

\section{Ensuring quality of care in sterilisation services}

\section{ABHIJ IT DAS}

SAHAYOG, C-2015 Indira Nagar, Lucknow, UP, India 226016. e-mail: abhiijtdas@ softhome.net

Female sterilisation is the mainstay of contraceptive methods in India. Every year over four million female sterilisation operations are conducted in the country. Like all surgical procedures, female sterilisation, despite being a relatively low-risk procedure, has its attendant risk and failure rates. According to international authorites, the failure rate, i.e. the chance of becoming pregnant after the operation is around one in 200 , the rate of complication around one in 100 (1), and the risk of death around three in 100,000 procedures (2). According to these estimates, there is a possibility of over 20,000 failures, 20,000 women with complications and about 150 deaths due to these operations. However, there are no specific provisions for dealing with these acceptable risks within the programme.

Healthwatch UP Bihar is an advocacy network on women's health and rights in four states-Uttar Pradesh, Bihar, Uttranchal and Jharkhand-which originally comprised UP and Bihar. Healthwatch UP Bihar is actively involved in tracking the changes in the delivery of the state family planning programme after the adoption of the Target Free Approach and after the Reproductive and Child Health Programme (3). The state unveiled its population policy in July 2000 and this policy had a set of escalating annual targets that ranged from 600,000 to 1.2 million cases per year. While reviewing the policy directives, members of the network came across a large number of cases of sterilisation failures, complications and deaths (4). Site visits to sterilisation camps revealed that bicycle pumps were being used to introduce air into the abdomen for laparoscopic ligation (5).

\section{Public interest litigation for ensuring quality of care in sterilisation services}

The Department of Family Welfare of the Government of India had prepared a manual of standards in the case of female and male sterilisation (6). The quality of care in 10 sterilisation camps was documented using these standards. It revealed that most of the standards were not being followed. The average operating time was between two and five minutes for laparoscopic ligation. Against the prescribed limit of 20 operations per team per day, teams were found to perform 75 operations.
Using the Healthwatch UP Bihar and another study as evidence, and the Department of Family Welfare guidelines as the basis, a public interest litigation (PIL) was filed in the Supreme Court by Healthwatch UP Bihar under Article 32 of the Constitution. The PIL (Writ Petition (Civil) No 209 2003) was admitted and the Supreme Court asked all states and union territories to file their affidavits. The Supreme Court gave its order to states in May 2003 and since then only seven states and union territories have filed their affidavits. These include Daman and Diu, Dadra and Nagar Haveli, Andaman and Nicobar islands, Sikkim, Manipur, Haryana and Orissa. Except for Haryana, none among these have acknowledged that there are any cases of failure, complication or death and have solemnly sworn that all procedures are following the standards. Haryana has been the sole exception because of the well-known Santara case (7) where the government had to pay compensation for the failure of a case of tubectomy.

It is interesting to note that a performance audit by the Comptroller and Auditor General (CAG) on the National Family Wefare Programme in 2001 reported that nine states had reported 762 failures and no investigations had been carried out to establish the reasons for the failure. A five-district study in Uttar Pradesh conducted in 1999 had reported a failure rate of $4.7 \%$ which would amount to over 15,000 failures in that state alone (8).

\section{Quality of care, ethics and law in the case of sterilisation}

Sterilisation campaigns have been in the centre of controversies. Forced sterilisations in Nazi Germany, in the US in the early 1940s and the Sterilisation Act of Sweden are well-known cases of human rights violations. There were forced sterilisations during the Emergency in India too. However, after the International Conference on Population and Development (Cairo 1994), family planning programmes have supposedly become more development-centred and women friendly. India too has changed its policies and programmes through the adoption of the National Population Policy (NPP 2000), the Reproductive and Child Health Programme (1997) and the Community Needs Assessment Approach (1999). 
In the wake of these changes, the findings of the two studies raise a number of legal and ethical questions regarding the conduct of individual operations, mass sterilisation camps as well as programme design and accountability.

There are close relationships between quality of care, ethics and legality. While quality of care can be considered to relate to technical aspects, ethics relate to the moral responsibility and law binds with legal accountability.

Sterilisation operations are non-therapeutic procedures and therefore warrant extra care and caution (9). The ethical responsibility of the practitioner is more in the case of nontherapeutic operations because it is possible to cause harm to someone who did not have a problem to start with. Many women undergo tubectomy as a result of the subtle pressures of health workers and the absence of knowledge and access to other services. The ethical considerations in the case of female sterilisation have more than one dimension. First, one has to consider the manner in which women are recruited for the procedure. While this is the responsibility of paramedics and outreach workers, it is finally the responsibility of the team headed by the operating surgeon to ensure that all medical eligibility criteria and ethical (informed consent) requirements have been met. The operating surgeons must ensure that the minimum acceptable technical standards are met. Besides, women who come to camps deserve to be treated with dignity. The author's experience at the camps shows that a heavily sedated woman is picked up roughly and dumped on the operation table. In the operation theatre, there is little concern for the woman's privacy and at the end of the operation she is picked up and dumped outside equally unceremoniously with little concern for post-operative care. As a programme of high national priority, the family planning programme owes the women who agree to undergo sterilisation operation, minimum respect and quality services and medical personnel associated with these camps need to ensure this.

Doctors often justify the shoddy treatment of women at sterilisation camps by referring to the pressure of targets that they have to fulfil or the lack of time. This is a dilemma that doctors must resolve at the personal level as well as through professional organisations such as the Indian Medical Association and Federation of Obstetrician and Gynaecologists Societies in India. The accountability to the employer (the government) in terms of the various pressures has to be balanced against the ethical responsibility towards the individual patient. Besides ethical principles, the consequences of poorly conducted operations have legal dimensions as well. Indian courts have admitted cases of tubectomy failure and deaths and have taken steps to compensate women both for medical negligence and fixed accountability of the state for negligence of the doctor in cases of failure (7) as well as tubectomy deaths (10).

It is time that the simple tubectomy operation is examined more closely not only because it is perhaps the most widely conducted surgical procedure in India but also because this major surgical procedure, if improperly performed, has the potential to cause harm.

\section{References}

1. Rotimi AK, Eedarapalli P. Female Sterilisation. Available from URL: http://www.sexualhealthmatters. com/v2iss2/article4.html (accessed on June 18, 2004).

2. Chapron C, Querleu D, Bruhat MA, et al. Surgical complications of diagnostic and operative gynaecological laparoscopy: a series of 29,966 cases. Hum Reprod 1998;13:867-72.

3. Healthwatch UP Bihar. Voices from the ground. Lucknow: Healthwatch UP Bihar, 1999.

4. Healthwatch UP Bihar. Priorities of the People. Lucknow: Healthwatch UP Bihar, 2002.

5. Saxena R. Theatre of the absurd. The Week, 22 December 2002.

6. Ministry of Health and Family Welfare. Standards for male and female sterilisation. Division of Research Studies \& Standards, Department of Family Welfare, MOHFW, Government of India, 1999.

7. Supreme Court in State of Haryana v. Santra [(2000) 5 Supreme Court Cases 182].

8. State Innovations for Family Planning Services Agency (SIFPSA). Laparoscopy Sterilisation: a study of success rate in the state of Uttar Pradesh. Lucknow, UP: SIFPSA, 1999 (mimeo).

9. Margaret AS. Therapeutic and non-therapeutic medical procedures-what are the distinctions? Health Law in Canada 1981;2:85-90.

10. Achutrao Haribhau Khodwa v. State of Maharashtra, 1996 Acc CJ 505 : (AIR 1996 SCW919) 